\title{
CD10/Neutral Endopeptidase 24.11 Regulates Fetal Lung Growth and Maturation In Utero by Potentiating Endogenous Bombesin-like Peptides
}

\author{
Katherine A. King, ** Ji Hua," John S. Torday, J Jeffrey M. Drazen," Sherry A. Graham, * Margaret A. Shipp," \\ and Mary E. Sunday* \\ Departments of *Pathology, ${ }^{\ddagger}$ Pediatrics and "Medicine, Harvard Medical School, ${ }^{* \|}$ Brigham \& Women's Hospital, and ${ }^{\ddagger}$ Children's \\ Hospital Medical Center, Boston, Massachusetts $02115 ;{ }^{\S}$ Department of Pediatrics, University of Maryland Medical School, Baltimore, \\ Maryland 21201; and 'Division of Medicine, Dana-Farber Cancer Institute, Boston, Massachusetts 02115
}

\begin{abstract}
Bombesin-like peptides ( BLPs ) are mitogens for bronchial epithelial cells and small cell lung carcinomas, and increase fetal lung growth and maturation in utero and in organ cultures. BLPs are hydrolyzed by the enzyme CD10/neutral endopeptidase 24.11 (CD10/NEP) which is expressed in bronchial epithelium and functions to inhibit BLP-mediated growth of small cell lung carcinomas. To determine whether CD10/NEP regulates peptide-mediated lung development, we administered a specific CD10/NEP inhibitor, SCH32615, to fetal mice in utero from gestational days e15-17. Fetal lung tissues were evaluated on $\mathrm{e} 18$ for: $(a)$ growth using $\left[{ }^{3} \mathrm{H}\right]$ thymidine incorporation into nuclear DNA; and (b) maturation using: $\left[{ }^{3} \mathrm{H}\right]-$ choline incorporation into surfactant phospholipids, electron microscopy for type II pneumocytes, and Northern blot analyses for surfactant apoproteins A, B, and C. Inhibition of CD10/ NEP stimulated $\left[{ }^{3} \mathrm{H}\right.$ ]thymidine incorporation into DNA $(\mathbf{7 0} \%$ above baseline, $P<0.005),\left[{ }^{3} \mathrm{H}\right]$ choline incorporation into surfactant phospholipids (38\% above baseline, $P<0.005$ ), increased numbers of type II pneumocytes ( $36 \%$ above baseline, $P=0.07)$, and fivefold higher surfactant protein A transcripts $(P<0.05)$. CD10/NEP-mediated effects were completely blocked by the specific bombesin receptor antagonist, [DPhe $^{12}$, Leu ${ }^{14}$ jbombesin. These observations suggest that CD10/NEP regulates fetal lung growth and maturation mediated by endogenous BLPs. (J. Clin. Invest. 1993. 91:19691973.) Key words: metalloendopeptidase - autocrine growth factors • fetal lung development • cell surface enzyme • common acute lymphoblastic leukemia antigen
\end{abstract}

\section{Introduction}

The cell membrane antigen $\mathrm{CD10/common} \mathrm{acute} \mathrm{lymphoblas-}$ tic leukemia antigen was shown by molecular cloning to be identical to the enzyme neutral endopeptidase 24.11 (NEP) ${ }^{1}$

Address correspondence to Dr. Mary E. Sunday, Brigham \& Women's Hospital, Department of Pathology, 75 Francis Street, Boston, MA 02115.

Received for publication 17 August 1992 and in revised form 30 November 1992.

1. Abbreviations used in this paper: BLP, bombesin-like peptide; e, embryonic day; GRP, gastrin-releasing peptide; LB, lamellar body; NEP, neutral endopeptidase 24.11; RT-PCR, reverse-transcribed PCR; SCLC, small cell lung carinoma; SP-, surfactant apoprotein(s); SPC, saturated phosphatidylcholine.

J. Clin. Invest.

(c) The American Society for Clinical Investigation, Inc. $0021-9738 / 93 / 05 / 1969 / 05 \$ 2.00$

Volume 91, May 1993, 1969-1973
(1-4). This zinc metalloprotease cleaves a variety of bioactive peptides including tachykinins such as bradykinin and substance P (2, 4-6). CD10/NEP downregulates neurogenic inflammation of the lung by modulating locally effective concentrations of tachykinins (7-10). The enzyme has been found to hydrolyze bombesin-like peptides (BLPs) within the conserved seven amino acid terminus required for biological activity (reviewed in 11,12,13). Recently, hydrolysis of BLPs by CD10/ NEP was demonstrated to modulate autocrine growth of small cell carcinomas of the lung (SCLCs): inhibition of CD10/NEP stimulated the growth of BLP-responsive SCLCs and addition of CD10/NEP inhibited the growth of SCLC in a dose-dependent fashion (12).

In addition to stimulating the autocrine growth of certain SCLCs, BLPs increase the clonal growth of adult human bronchial epithelial cells and the proliferation of pulmonary fibroblasts (14-16). In recent studies, these peptides were also shown to stimulate the proliferation and maturation of normal fetal lung. Gastrin-releasing peptide (GRP; mammalian bombesin ) transcripts and immunoreactivity were detectable in pulmonary neuroendocrine cells of human fetal lung as early as 8 wk gestation, with peak transcript levels occurring at midgestation (17). In murine fetal lung, maximal GRP expression occurred on embryonic days 17 and 18 (e17-18). Exogenous bombesin administered to pregnant mice during this time period stimulated the proliferation and maturation of fetal lung as assessed by functional, biochemical, and ultrastructural analyses. In related studies, BLPs stimulated the proliferation and maturation of human fetal lung organ cultures (18).

Those studies demonstrated that CD10/NEP was expressed by immature bronchial epithelial cells in first trimester human fetal lung and that inhibition of the enzyme was associated with increased proliferation of human fetal lung organ cultures. To further explore the role of CD10/NEP in fetal lung development in utero, we administered a long-acting inhibitor of CD10/NEP (SCH32615) to pregnant mice and subsequently evaluated parameters of both fetal lung proliferation and maturation. Herein, we report that the inhibition of CD10/NEP results in a significant enhancement of fetal lung growth and maturation that is completely blocked by a specific bombesin receptor antagonist.

\section{Methods}

Reverse-transcribed PCR (RT-PCR) analyses for CD10/NEP and actin transcripts. Lungs were harvested from untreated fetal mice on the morning of gestational days 12-18 (e12-18) and total RNA was prepared using the quanidine isothiocyanate (GTC)-CsCl method (19). RNA (obtained from three to eight litters for each time point) was reverse transcribed and CDNA was amplified by PCR as previously described using actin primers (20) and CD10/NEP primers corresponding to $1208-1228$ and $1667-1648$ bp of mouse CD10 sequence 
(21). Southern blots of the PCR products were probed with an end-labeled internal oligonucleotide specific for either CD10/NEP (1319$1338 \mathrm{bp}$ ) or actin (20). For semi-quantitative RT-PCR, conditions were determined such that the number of cycles was approximately one-third maximal and thus within the linear range of detection. Furthermore, increased RNA input led to a linear increase in RT-PCR signal for both actin and CD10/NEP (comparing three doses over a two log scale). Therefore, there was a linear correlation between the relative amounts of given mRNAs present in the products of the same reverse transcription reaction, which could then be compared to actin as a control reference housekeeping mRNA.

In vivo administration of SCH32615 to pregnant mice. We chose to administer SCH32615 (Schering-Plough Corp., Bloomfield, NJ) from e15-17 because BLP effects were most apparent at e17-18 in previous studies (22) and peak CD10/NEP transcript levels occurred at e15-18 by Northern blotting (data not shown) and reverse PCR analyses (Fig. 1). $\mathrm{SCH} 32615$ was given i.p. to timed-pregnant $\mathrm{CD}$ mice as a single loading dose of 0.4 or $4.0 \mathrm{mg} / \mathrm{kg}$ in PBS at 8 a.m. of gestational day 15 and subsequent additional doses of 0.1 or $1.0 \mathrm{mg} / \mathrm{kg}$ at $6 \mathrm{p} . \mathrm{m}$. and 8 a.m. daily through the morning of day 17 (birth is on day 18). This dose range was selected because previous studies indicated that $10 \mu \mathrm{M}$ was an analgesic dose in the rat footpad assay (23). The $10-\mu \mathrm{M}$ dose is calculated to be $\sim 1 \mathrm{mg} / \mathrm{kg}$ when body fluid in an adult mouse is estimated to be $60 \%$ of total body weight. In certain experiments, mice were also given $100 \mu \mathrm{g} / \mathrm{kg}$ of a specific bombesin receptor antagonist, [D-Phe ${ }^{12}$, Leu $^{14}$ ]bombesin (24), as part of the mixture for each i.p. injection on days 15-17. In selected experiments, mice were similarly injected from day 12 to day 14. Pregnant mice were killed on the afternoon of day 17 or 18 of gestation by cervical dislocation. The pups were removed by laparotomy, killed before breathing, and lungs removed for biochemical, histological, and ultrastructural analyses. The animal use protocol was approved by the Brigham \& Women's Hospital Animal Ethics Committee and care of the mice used in these experiments was in accordance with institutional (National Institutes of Health) guidelines.

Determination of saturated phosphatidylcholine (SPC), protein, and DNA content. Fetal lungs were cut into $1-\mathrm{mm}$ cubes in MEM on ice and incubated with $\left[{ }^{3} \mathrm{H}\right]$ choline $(16 \mu \mathrm{Ci} / \mathrm{ml})$ or $\left[{ }^{3} \mathrm{H}\right]$ thymidine $(4$ $\mu \mathrm{Ci} / \mathrm{ml}$ ) for $4 \mathrm{~h}$ at $37^{\circ} \mathrm{C}$ in $5 \% \mathrm{CO}_{2} /$ air on a rocking platform. Tissues were harvested and analyzed for ${ }^{3} \mathrm{H}$-labeled DNA, DNA content, ${ }^{3} \mathrm{H}-$ labeled SPC, and protein content as outlined below.

For determination of ${ }^{3} \mathrm{H}$-SPC, lipids were extracted from cell homogenates with chloroform/methanol and $\left[{ }^{3} \mathrm{H}\right]$ choline incorporation into phosphatidylcholine was determined as previously described (22). Protein was determined by the method of Bradford with BSA as standard $(25) .\left[{ }^{3} \mathrm{H}\right]$ thymidine incorporation into acid-precipitable counts was carried out as previously described (26). DNA was assayed after trichloroacetic acid precipitation by the method of Burton (27). Experimental values were normalized by defining the mean of the control groups as baseline and expressing values as percentage increases above or below control values.

Ultrastructural analyses. Pregnant mice were treated from gestational days 15-17 with either PBS or SCH32615 $(0.1$ and $1.0 \mathrm{mg} / \mathrm{kg})$. Lungs were harvested on e18, fixed in $2.5 \%$ glutaraldehyde / $1 \%$ paraformaldehyde, and routinely processed for electron microscopic analyses. Blocks were selected within a group such that both proximal and distal portions of the lung were equally represented for each of the four groups. The number of nucleated epithelial cells containing lamellar bodies (LBs) was quantitated by an observer without knowledge of the experimental protocol on $\times 2,000$ electron micrographs. The mean number of LB-positive cells per total number of nucleated epithelial cells was determined where each cell was $\sim 4-10 \mu \mathrm{m}$ in width. The number of LBs per LB-positive cell was quantitated and expressed as the mean number per positive cell.

Northern (RNA) blot hybridization. Total RNA was prepared from freshly harvested fetal lung tissues using the guanidinium isothiocyanate-cesium chloride method (28). $10 \mu \mathrm{g} /$ lane of total RNA was fractionated on formaldehyde denaturing agarose gels and transferred to nitrocellulose by standard capillary transfer (19). After baking, blots were prehybridized for $12 \mathrm{~h}$. The blots were probed with cDNAs encoding murine CD10/NEP (29), surfactant apoproteins (SPA) A, B, and C (kindly donated by Dr. Joanna Floros, Pennsylvania State University, Hershey, PA [30]) and a housekeeping G-protein (G-alpha ${ }_{\mathrm{i} 2}$, donated by Dr. Randall Reed, Johns Hopkins University School of Medicine, Baltimore, MD [31]). cDNA probes were synthesized from gelpurified cDNA inserts corresponding to coding sequences from mouse CD10/NEP (2,400 bp), rat SP-A ( 750 bp), SP-B (500 bp), and SP-C $(800 \mathrm{bp})$, and $\mathrm{G}$-protein $(1,800 \mathrm{bp})$ using the random-primed oligonucleotide method (32). Blots were hybridized with $10^{6} \mathrm{cpm} / \mathrm{ml}$ at $42^{\circ} \mathrm{C}$ for $24 \mathrm{~h}$ in hybridization buffer: $40 \%$ formamide; $4 \times$ SSC; $10 \%$ dextran sulfate; $1 \times$ Denhardt's solution $(1 \times$ Denhardt's = polyvinylpyrrolidone [ $20 \mathrm{mg} \%$ ], BSA [ $20 \mathrm{mg} \%$ ], Ficoll 400 [ $20 \mathrm{mg} \%$ ]; sonicated denatured salmon sperm DNA [ $500 \mu \mathrm{g} / \mathrm{ml}$ ]; Tris, $20 \mathrm{mM}$, pH 7.4). After washing at $42^{\circ} \mathrm{C}$ in $2 \times \mathrm{SSC}, 0.1 \% \mathrm{SDS}$, blots were exposed overnight to Kodak XAR film with an intensifying screen and subsequently developed. Densitometry was carried out by three-dimensional integration of the area of whole bands on autoradiograms using a densitometer (model 300A; Molecular Dynamics, Inc., Sunnyvale, CA).

Statistical analyses. Data were statistically analyzed using the unpaired Student's $t$ test.

\section{Results}

$C D 10 / N E P$ transcript levels in fetal mouse lung. CD10/NEP transcript levels were detectable at low levels as early as e 12 by semi-quantitative reverse PCR analyses (Fig. 1). Peak CD10/ NEP transcript levels occurred at e 15-18 by reverse PCR analyses (Fig. 1) and by Northern blotting (data not shown).

In vivo studies. There was no significant difference between saline controls and SCH32615-treated fetal mice with regards to intrauterine viability, total fetal weight, or developmental defects. No histological differences were observed between saline controls and SCH32615-treated animals by light microscopic examination on e17-18. In both sets of animals, all cells lining the primitive alveoli were simple cuboidal as expected for the canalicular and saccular stages of murine lung development during this time period.

We chose to administer SCH32615 from e15-17 because BLP effects were most apparent at e17-e18 in previous studies (22) and peak CD10/NEP transcript levels occurred at e17-18 (Fig. 1). The administration of SCH32615 from e15-17 in

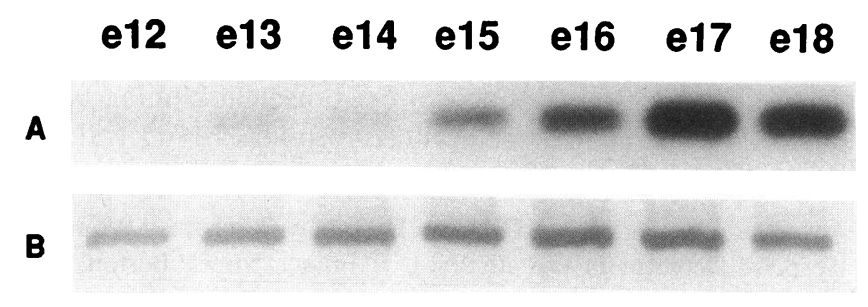

Figure 1. CD10/NEP transcript levels in fetal mouse lung. Lungs were harvested from untreated fetal mice on the morning of e12-18 and total RNA was prepared using the GTC-CsCl method (19). RNA (obtained from three to eight litters for each time point) was reverse transcribed and CDNA was amplified by PCR as previously described using actin primers (20) and CD10/NEP primers corresponding to 1,208-1,228 and 1,667-1,648 bp of mouse CD10 sequence (21). Southern blots of the PCR products were probed with an end-labeled internal oligonucleotide specific for the gene product of interest: $(A)$ CD10/NEP (1,319-1,338 bp); (B) actin (20). Conditions were defined such that the RT-PCR analyses were semiquantitative, with increased RNA input leading to a linear increase in signal for both actin and CD10/NEP. 
utero led to increased fetal lung growth as assessed by incorporation of $\left[{ }^{3} \mathrm{H}\right]$ thymidine into nuclear DNA. In Fig. $2 A$, the pooled data from nine experiments are shown. Both the 0.1 and $1.0 \mathrm{mg} / \mathrm{kg}$ doses of SCH32615 led to significantly elevated thymidine incorporation in murine fetal lungs harvested on e18 $(0.1 \mathrm{mg} / \mathrm{kg}$ : $17 \%$ increase, $P<0.05$; and $1.0 \mathrm{mg} / \mathrm{kg}: 69 \%$ increase, $P<0.005$, respectively, Fig. $2 A$ ).

To determine whether CD10/NEP inhibition also affected fetal lung maturation, we measured the incorporation of $\left[{ }^{3} \mathrm{H}\right]-$ choline into SPC, a key rate-determining step in the biochemical pathway of surfactant phospholipid synthesis. Pooled data from nine experiments are shown in Fig. $2 B$. In animals treated with SCH32615, significantly elevated choline incorporation was observed on e18 (38\% increase, $1.0 \mathrm{mg} / \mathrm{kg}$ dose, $P$ $<0.005$ ). Fetal serum corticosterone levels did not differ between PBS controls and SCH32615-treated mice (data not shown).

To determine whether the in vivo effect of SCH32615 was mediated by BLPs, mice were concurrently treated with 100 $\mu \mathrm{g} / \mathrm{kg}$ of a specific bombesin receptor antagonist, [D-Phe ${ }^{12}$, Leu ${ }^{14}$ ]bombesin (24) (BR in Fig. 2) and SCH32615 (1.0 mg/

\section{THYMIDINE INCORPORATION}

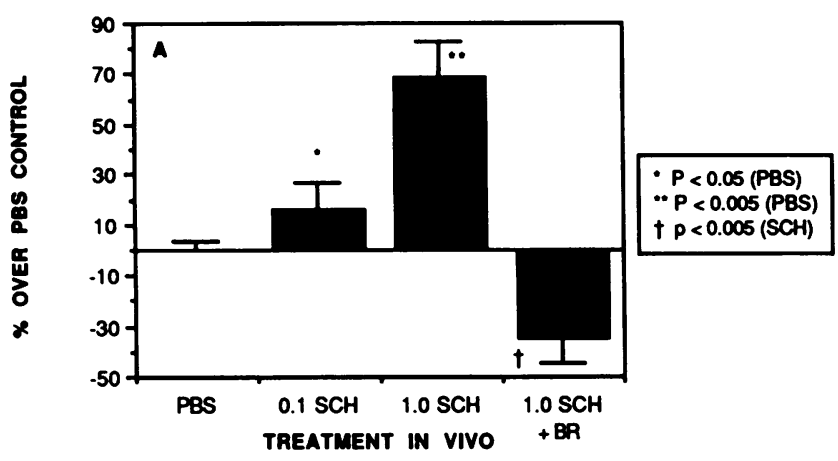

CHOLINE INCORPORATION

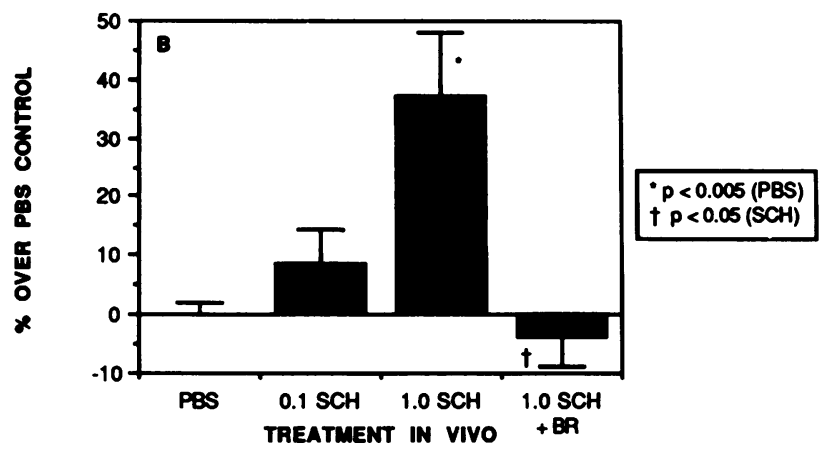

Figure 2. Thymidine and choline incorporation in murine fetal lung after CD10/NEP inhibition. Timed pregnant mice were treated from e 15-17 with either PBS alone or 0.1 or $1.0 \mathrm{mg} / \mathrm{kg} \mathrm{SCH} 32615$ in PBS and fetal lungs were harvested on e18. Certain animals received the specific antagonist [D-Phe ${ }^{12}$, Leu ${ }^{14}$ ]bombesin $(100 \mu \mathrm{g} / \mathrm{kg})(B R)$ in addition to $\mathrm{SCH} 32615(1 \mathrm{mg} / \mathrm{kg}) .(A)\left[{ }^{3} \mathrm{H}\right]$ Thymidine incorporation in fetal lung normalized for total DNA content per sample. $(B)\left[{ }^{3} \mathrm{H}\right]-$ Choline in fetal lung normalized for total protein content per sample. Results of nine experiments are expressed as percentage increase over baseline (PBS controls; 16 to 58 values per group, each value representing two to three fetal lungs). Bars represent \pm 1 SE of the mean. $P$ values are given with respect to PBS controls for SCH32615 alone and with respect to $\mathrm{SCH}(1 \mathrm{mg} / \mathrm{kg})$ for $\mathrm{SCH}+\mathrm{BR}$. $\mathrm{kg}$ ) from e15-17 in four experiments. Fetal lungs were again harvested on e18. As shown in Fig. 2, $A$ and $B$, SCH32615-stimulated thymidine and choline incorporation were both significantly blocked by [D-Phe ${ }^{12}$, Leu $^{14}$ ]-bombesin $(P<0.005$ and 0.05 , respectively). [D-Phe ${ }^{12}$, Leu ${ }^{14}$ ]bombesin alone did not inhibit baseline lung growth or automaturation at the $100 \mu \mathrm{g} /$ $\mathrm{kg}$ dose (data not shown).

To determine whether the inhibition of CD10/NEP might affect the earlier embryonic and pseudoglandular stages of lung development (e12-e16), SCH32615 (1 mg/kg) was administered to pregnant mice from e12-14. Fetal lung tissues were harvested from treated and control animals on e14, 15, 16, and 17. Pooled results from three experiments are shown in Fig. 3. The administration of SCH32615 from e12-14 did not affect thymidine incorporation in e14 murine fetal lungs. However, e12-14 CD10/NEP inhibition increased thymidine incorporation in e15-17 fetal lungs (e15, 18\% increase, $P<0.05$; e16, $37 \%$ increase, $P<0.005$; and e17, 107\% increase, $P<0.05$, respectively). Early SCH32615 administration resulted in increased thymidine and choline incorporation on e 18 that was similar to that observed using the e15-e17 injection schedule (Fig. 2 and data not shown).

Electron microscopy. LBs are one of the morphological manifestations of surfactant and are thus a sensitive indicator of early type II pneumonocyte differentiation, which is a critical step in lung maturation. For this reason, we performed ultrastructural analyses for LBs in fetal lungs of SCH32615treated animals (Fig. 4). The relative numbers of LB-positive cells lining primitive alveoli were determined and the number of LBs per cell quantitated. A trend towards increased type II cell differentiation was observed on e18 in SCH32615-treated animals (Fig. $4 A$ ) . LB-positive cells represented only $17.8 \%$ of the alveolar lining cells in PBS controls in contrast to $24.2 \%$ in SCH32615-treated mice ( $36 \%$ increase, $P=0.07$ ). There was also a significant decrease in the number of LBs per LB-positive

\section{THYMIDINE INCORPORATION}

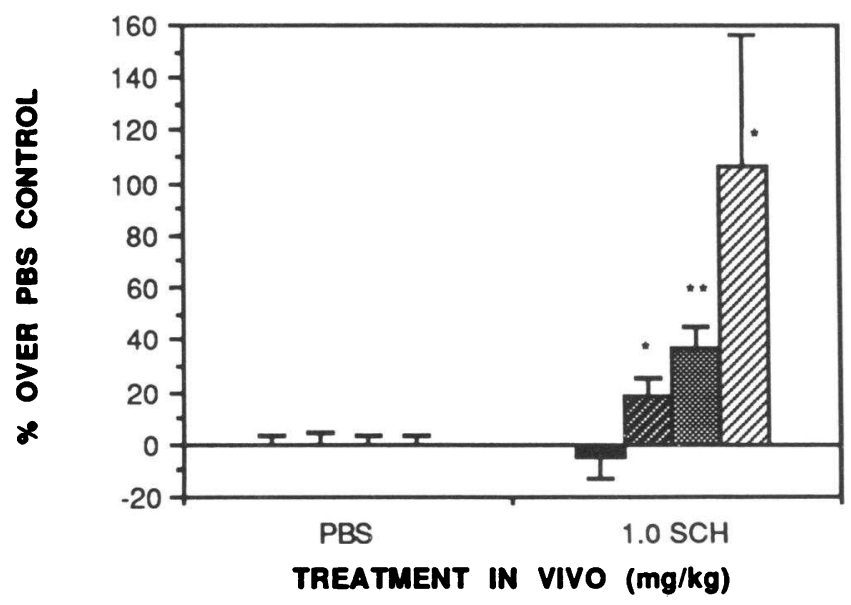

Figure 3. Kinetics of growth stimulation in murine fetal lung after CD10/NEP inhibition. Fetal mice were treated transplacentally with $\mathrm{SCH} 32615(1.0 \mathrm{mg} / \mathrm{kg})$ from e12-14 as detailed in Methods. Fetal lung tissues were harvested at 24-h intervals (e14-e17) and thymidine incorporation was determined with respect to PBS controls harvested on the same day. Pooled results from three experiments are shown in Fig. 3. $P$ values are with respect to PBS controls on the same day. $\square$,

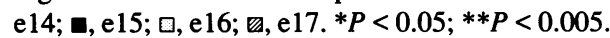


\% LB-Positive Alveolar Lining Cells

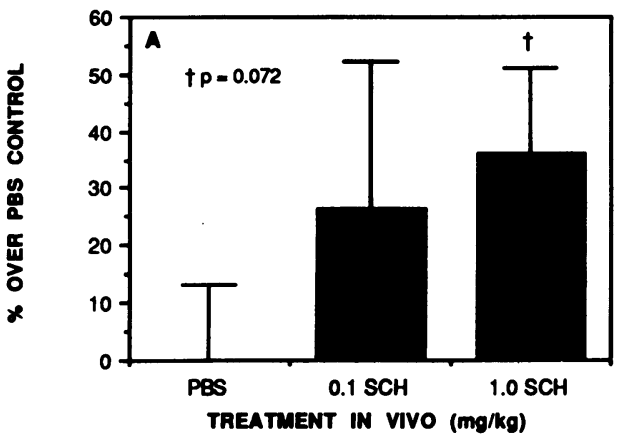

* LBs per LB-Positive Cell

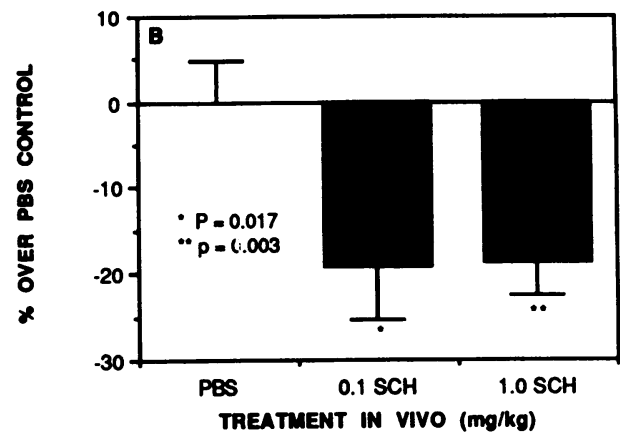

Figure 4. Ultrastructural analyses for lamellar bodies in fetal lung after CD10/ NEP inhibition. Pregnant mice were treated with $\mathrm{SCH} 32615(0.1$ or $1.0 \mathrm{mg}$ / $\mathrm{kg}$ ) from e15-17 and tissues were harvested on 18 for routine transmission electron microscopy ( two pooled experiments, with two fetal lungs per group per experiment). Morphometric analyses were carried out to determine the percentage of al-

veolar lining cells that contained LBs $(A)$ as well as the number of LBs per LB-positive cell $(B)$. Results are expressed as percent change over baseline (PBS controls), with corresponding $P$ values as indicated.

cell (1.5-1.2, $P<0.005)$ in SCH32615-treated animals (Fig. 4 $B$ ) suggesting that $\mathrm{CD10} / \mathrm{NEP}$ inhibition may be associated with increased surfactant secretion.

Northern blot analyses. To further assess the effects of CD10/NEP inhibition on fetal lung maturation, surfactant apoprotein transcript levels were determined as a highly specific indicator of ongoing surfactant synthesis. Northern blots were normalized using a pulmonary housekeeping G-protein $\left(\mathrm{G}\right.$-alpha $\left.\mathrm{i}_{\mathrm{i} 2}\right)$ that is unchanged during normal lung development (31). SP-A transcripts were detected at high levels in only one of six PBS control litters, as compared to three of five litters treated with SCH32615 (Fig. $4 A$ ). The SP-A transcripts were quantitated by densitometry (Fig. 5) and normalized for G-
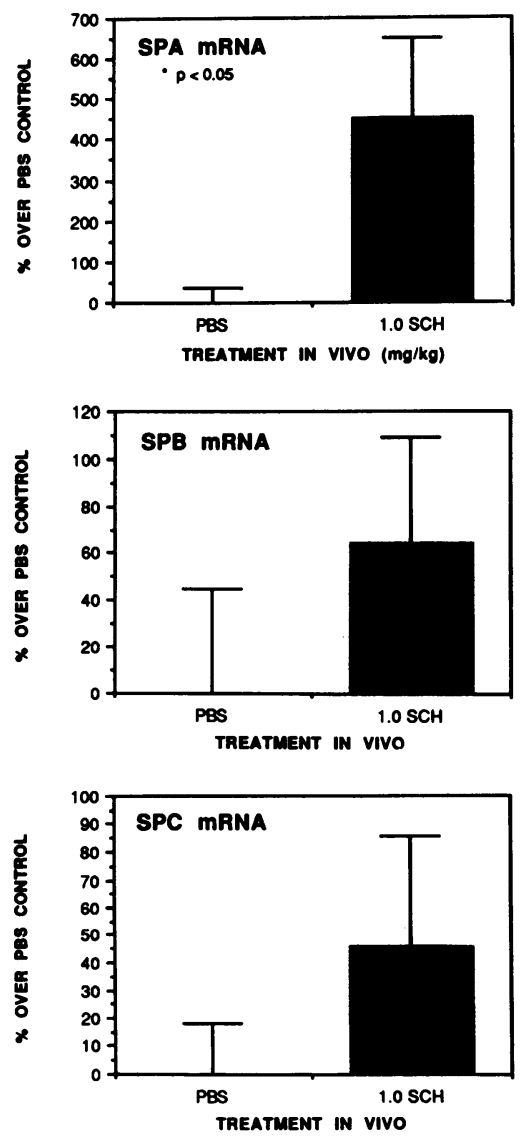

Figure 5. Relative levels of surfactant apoprotein mRNAs in fetal lung after CD10/NEP inhibition. Pregnant mice were treated with $\mathrm{SCH} 32615(1.0 \mathrm{mg} / \mathrm{kg})$ from e15-17 and total RNA prepared from fetal lung tissues on e18 using the GTC-CsCl method (19). RNA from three to six mice per litter were pooled so that on Northern blots each lane represented a single litter. Relative SP-A, SP-B, and SP-C transcript levels were determined by densitometry, normalized for relative G-protein transcript levels, and expressed as mean percent change over baseline $(\mathrm{PBS}) \pm 1 \mathrm{SE}$. protein levels. As shown in Fig. 5, the fivefold increase in SPA transcripts in SCH32615-treated animals was statistically significant $(P<0.05)$. SP-B and SP-C transcript levels were also increased by $50-60 \%$ in fetal lungs from SCH32615-treated animals (Fig. 5).

\section{Discussion}

The present study demonstrates stimulation of fetal lung growth and maturation in mice treated in utero with SCH32615, a long acting CD10/NEP inhibitor. Increased growth was evaluated using $\left[{ }^{3} \mathrm{H}\right]$ thymidine incorporation. Increased maturation was assessed using $\left[{ }^{3} \mathrm{H}\right]$ choline incorporation into SPC, ultrastructural morphometry for type II pneumocytes, and Northern blot analyses for SP-A, SP-B, and SP-C transcript levels. The effects of CD10/NEP inhibition on thymidine and choline incorporation were blocked when animals were also treated with a specific bombesin receptor antagonist, implicating endogenous BLPs as mediators of the SCH32615 effect in vivo.

Both CD10/NEP inhibition and the administration of exogenous BLP stimulate fetal lung growth and maturation on e18. In previous studies, peak levels of the mammalian bombesin homologue, GRP, were detectable on e18 and exogenous BLP administration stimulated e18 fetal lung growth and maturation (22). That CD10/NEP inhibition similarly stimulates e18 fetal lung growth and maturation is consistent with these observations. CD10/NEP inhibition has the greatest effects on fetal lung growth and maturation during the time frame in which endogenous fetal lung CD10/NEP transcript levels are most abundant ( e16-18). Although SCH32615 administration in utero from e12-14 had little effect on e14 lung growth, significantly greater effects were seen at e16-18. Similarly, SCH32615 administration from e15-17 markedly enhanced e18 fetal lung development.

CD10/NEP is known to regulate the BLP-mediated autocrine growth of SCLCs. The present study further indicates that the enzyme also regulates BLP-mediated paracrine growth and maturation of normal fetal lung. Since the in vivo administration of SCH32615 results in increased fetal lung maturation, CD10/NEP inhibition may be of therapeutic benefit for premature infants at high risk for developing hyaline membrane disease $(33,34)$.

There are a number of parallels between the pulmonary and lymphoid expression of CD10/NEP during normal fetal 
development. In the fetus, undifferentiated epithelial cells in the most distal airways and early lymphoid progenitors that are either uncommitted or committed to only the earliest stages of $B$ or $T$ cell differentiation express CD10/NEP. The enzyme may have similar roles in these distinct cell types because inhibition of CD10/NEP also stimulates the growth and maturation of murine lymphoid progenitors in in vitro assays (29; Salles, G., H.-R. Rodewald, B. S. Chin, E. L. Reinherz, and M. A. Shipp, manuscript submitted for publication). Therefore, the identification of CD10/NEP as a regulator of BLP-mediated growth and maturation of fetal lung suggest that the enzyme may play a role in modulating growth and maturation in other organ systems as well.

\section{Acknowledgments}

We thank Dr. Mary Ellen Avery for helpful discussions.

This work was supported by National Institutes of Health grant R01-HL44984 (M. E. Sunday).

\section{References}

1. Shipp, M. A., N. E. Richardson, P. H. Sayre, N. R. Brown, E. L. Mastellar, L. K. Clayton, J. Ritz, and E. L. Reinherz. 1988. Molecular cloning of the common acute lymphoblastic leukemia antigen (CALLA) identifies a type II integral membrane protein. Proc. Natl. Acad. Sci. USA. 85:4819-4823.

2. Shipp, M. A., J. Vijayaraghavan, E. V. Schmidt, E. L. Masteller, L. D'Adamio, L. B. Hersh, and E. L. Reinherz. 1989. Common acute lymphoblastic leukemia antigen (CALLA) is active neutral endopeptidase 24.11 ("enkephalinase"): direct evidence by cDNA transfection analysis. Proc. Natl. Acad. Sci. USA. 86:297-301.

3. D'Adamio, L., M. A. Shipp, E. L. Masteller, and E. L. Reinherz. 1989. Organization of the gene encoding common acute lymphoblastic leukemia antigen ( neutral endopeptidase 24.11): multiple miniexons and separate 5' untranslated regions. Proc. Natl. Acad. Sci. USA. 86:7103-7107.

4. LeTarte, M., S. Vera, R. Tran, J. B. L. Addis, R. J. Onizuka, E. J. Quackenbush, C. V. Jongeneel, and R. R. McInnes. 1988. Common acute lymphocytic leukemia antigen is identical to neutral endopeptidase. J. Exp. Med. 168:12471253.

5. Erdos, E. G., and R. A. Skidgel. 1989. Neutral endopeptidase 24.11 (enkephalinase) and related regulators of peptide hormones. FASEB (Fed. Am. Soc Exp. Biol.) J. 3:145-151.

6. Kenny, A. J., M. J. O'Hare, and B. A. Gusterson. 1989. Cell-surface peptidases as modulators of growth and differentiation. Lancet. ii:785-787.

7. Martins, M. A., S. A. Shore, N. P. Gerard, C. Gerard, and J. M. Drazen. 1990. Peptidase modulation of the pulmonary effects of tachykinins in tracheal superfused guinea pig lungs. J. Clin. Invest. 85:170-176.

8. Nadel, J. A., and D. B. Borson. 1991. Modulation of neurogenic inflammation by neutral endopeptidase. Am. Rev. Respir. Dis. 143(Suppl.):S33-S36.

9. Nadel, J. A. 1990. Decreased neutral endopeptidases: possible role in inflammatory diseases of airways. Lung. (Suppl.):123-127.

10. Stimler-Gerard, N. P. 1987. Neutral endopeptidase-like enzyme controls the contractile activity of Substance $P$ in guinea pig lung. J. Clin. Invest. 79:18191825.

11. Sunday, M. E., L. M. Kaplan, E. Motoyama, W. W. Chin, and E. R. Spindel. 1988. Biology of disease: gastrin-releasing peptide (mammalian bombesin) gene expression in health and disease. Lab. Invest. 59:5-24.

12. Shipp, M. A., G. E. Tarr, C.-Y. Chen, S. N. Switzer, L. B. Hersh, H. Stein, M. E. Sunday, and E. L. Reinherz. 1991. CD10/NEP hydrolyzes bombesin-like peptides and regulates the growth of small cell carcinomas of the lung. Proc. Natl. Acad. Sci. USA. 88:10662-10666.

13. Bunnett, N. W., R. Kobayashi, M. S. Orloff, J. R. Reeve, A. J. Turner, and
J. H. Walsh. 1985. Catabolism of gastrin releasing peptide and substance $P$ by gastric membrane-bound peptidases. Peptides (Elmsford). 6:277-283.

14. Willey, J. C., J. F. Lechner, and C. C. Harris. 1984. Bombesin and the C-terminal tetradecapeptide of gastrin-releasing peptide are growth factors for normal human bronchial epithelial cells. Exp. Cell Res. 153:245-248.

15. Cuttitta, F., D. N. Carney, J. Mulshine, T. W. Moody, J. Fedorko, A. Fischler, and J. D. Minna. 1985. Bombesin-like peptides can function as autocrine growth factors in human small cell cancer. Nature (Lond.). 316:823-826.

16. Aguayo, S. M., T. E. King, J. A. Waldron, K. M. Sherritt, M. A. Kane, and Y. E. Miller. 1990. Increased pulmonary neuroendocrine cells with bombesinlike immunoreactivity in adult patients with eosinophilic granuloma. J. Clin. Invest. 86:838-844.

17. Spindel, E. R., M. E. Sunday, H. Hofler, H. J. Wolfe, J. F. Habener, and W. W. Chin. 1987. Transient elevation of mRNAs encoding gastrin-releasing peptide (GRP), a putative pulmonary growth factor, in human fetal lung. J. Clin. Invest. 80:1172-1179.

18. Sunday, M. E., J. Hua, J. Torday, B. Reyes, and M. A. Shipp. 1992. CD10/Neutral endopeptidase 24.11 in developing human fetal lung: patterns of expression and modulation of peptide-mediated proliferation. J. Clin. Invest. 90:2517-2525.

19. Davis, L. G., M. D. Dibner, and J. F. Battey. 1986. Basic Methods in Molecular biology. Elsevier Science Publishing Co., Inc., New York. 1-388.

20. Sunday, M. E., and C. G. Willett. 1992. Induction and spontaneous regression of intense pulmonary neuroendocrine cell differentiation in a model of preneoplastic lung injury. Cancer Res. 52(Suppl.):2677s-2686s.

21. Chen, C.-Y., G. Salles, M. F. Seldin, A. E. Kister, E. L. Reinherz, and M. A. Shipp. 1992. Murine common acute lymphoblastic leukemia antigen (CD10/neutral endopeptidase 24.11): molecular characterization, chromosomal localization, and modeling of the active site. J. Immunol. 148:2817-2825.

22. Sunday, M. E., J. Hua, H. B. Dai, A. Nusrat, and J. S. Torday. 1990. Bombesin increases fetal lung growth and maturation in utero and in organ culture. Am. J. Respir. Cell Mol. Biol. 3:199-205.

23. Chipkin, R. E., J. G. Berger, W. Billard, L. C. Iorio, R. Chapman, and A. Barnett. 1988. Pharmacology of SCH 34826, an orally active enkephalinase inhibitor analgesic. J. Pharmacol. Exp. Ther. 245:829-838.

24. Heinz-Erian, P., D. H. Coy, M. Tamura, S. W. Jones, J. D. Gardner, and R. T. Jensen. 1987. [D-Phe ${ }^{12}$ ]bombesin analogues: a new class of bombesin receptor antagonists. Am. J. Physiol. 252:G439-G442.

25. Bradford, M. M. 1976. A rapid and sensitive method for the quantitation of microgram quantities of protein utilizing the principle of protein-dye binding. Anal. Biochem. 72:248-254.

26. Rozengurt, E., and J. Sinnett-Smith. 1983. Bombesin stimulation of DNA synthesis and cell division in cultures of Swiss 3T3 cells. Proc. Natl. Acad. Sci. USA. 80:2936-2940.

27. Burton, K. 1956. A study of the conditions and mechanism of the diphenylamine reaction for the colorimetric estimation of deoxyribonucleic acid. Biochemistry. 62:315-322.

28. Chirgwin, J. M., A. E. Przybyla, R. J. MacDonald, and W. J. Rutter. 1979. Isolation of biologically active ribonucleic acid from sources enriched in ribonuclease. Biochemistry. 18:5294-5299.

29. Salles, G., C.-Y. Chen, E. L. Reinherz, and M. A. Shipp. 1992. CD10/ NEP is expressed on Thy- ${ }^{\text {low }}$ B220+ murine B-cell progenitors and functions to regulate stromal cell dependent lymphopoiesis. Blood. 80:2021-2029.

30. Phelps, D. S., and J. Floros. 1991. Localization of pulmonary surfactant proteins using immunohistochemistry and tissue in situ hybridization. Exp. Lung Res. 17:985-995.

31. Jones, D. T., and R. R. Reed. 1987. Molecular cloning of five GTP-binding protein cDNA species from rat olfactory neuroepithelium. J. Biol. Chem 262:14241-14249.

32. Feinberg, A. P., and B. Vogelstein. 1983. A technique for radiolabeling DNA restriction endonuclease fragments to high specific activity. Anal. Biochem. 132:6-13.

33. Schellhase, D. E., and J. M. Shannon. 1991. Effects of maternal dexamethasone on expression of SP-A, SP-B, and SP-C in the fetal rat lung. Am. J. Respir. Cell Mol. Biol. 4:304-312.

34. Ballard, P. L. 1989. Hormonal regulation of pulmonary surfactant. Endocr. Rev. 10:165-181. 